\title{
Tire Combustion Emissions and Their Histochemical Implications on the Lung Tissues of Albino Mice
}

\author{
Josephate Bosire, Joshua Kibet*, Thomas Kinyanjui, Benson Githaiga \\ Department of Chemistry, Egerton University, Egerton, Kenya \\ Email: *jkibet@egerton.ac.ke
}

How to cite this paper: Bosire, J., Kibet, J., Kinyanjui, T. and Githaiga, B. (2016) Tire Combustion Emissions and Their Histochemical Implications on the Lung Tissues of Albino Mice. Open Access Library Journal, 3: e3076.

http://dx.doi.org/10.4236/oalib.1103076

Received: September 20, 2016

Accepted: October 16, 2016

Published: October 19, 2016

Copyright $\odot 2016$ by authors and Open Access Library Inc.

This work is licensed under the Creative Commons Attribution International

License (CC BY 4.0).

http://creativecommons.org/licenses/by/4.0/

\section{(c) (i) Open Access}

\begin{abstract}
Organic volatiles and particulate emissions from the combustion of tire are believed to contain eco-toxic substances including polycyclic aromatic hydrocarbons (PAHs) and various reactive radical species which may initiate serious respiratory ailments such as asthma and lung tumors. This study investigates the nature and toxicological effects of particulate soot from tire burning. To simulate environmental pollution, 12-week-old male albino mice were exposed to tire particulate emissions at a rate of

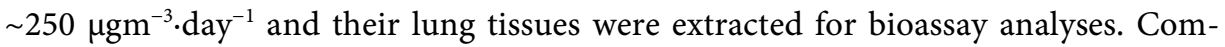
parisons were made between the lung tissues of mice exposed to the particulate emissions, and the control mouse in order to determine the health impact of particulates on the functioning of the lung soft tissue. The thermal degradation profile of tire was also investigated in the temperature range $200^{\circ} \mathrm{C}-500^{\circ} \mathrm{C}$ and found that the highest mass loss was between $300^{\circ} \mathrm{C}$ and $450^{\circ} \mathrm{C}$. Organic volatiles were determined using a Gas Chromatograph coupled to a mass selective detector (MSD). Size distribution of soot particles was determined using Scanning electron microscope (SEM). Evidently, there was swelling and shrinking of lung tissue cells as a result of exposure to tire particulate emissions which caused disconnection of tissues and damage to the blood capillaries within the lung alveoli and microphages. Organic volatiles detected from tire combustion include benzene, anthracene, fluorene and pyrene. Soot particulate average sizes were found to be $16.23 \pm 3.36 \mu \mathrm{m}$. Tire particulates caused grave damage to the lung tissues of the mice. These effects may be attributed to toxic organic volatiles as well as particulate emissions which may contain reactive active radicals and toxic organic intermediates and thus cause grave damage to the lung tissues of the mice.
\end{abstract}

\section{Subject Areas}

Environmental Chemistry, Environmental Sciences 


\section{Keywords}

Lungs, Histochemistry, Emissions, Eco-Toxicants

\section{Introduction}

The contribution discusses the particulate emissions from tire combustion and their histochemistry on research mice and extrapolates it to the human environment. The disposal of used tires has led to serious environmental health hazards, especially when large stockpiles of tires are burnt [1]. The emissions from the burning of tires are associated with serious public health ailments including whizzing of the lungs and chronic coughs. Precisely, emissions from burning tires are highly mutagenic and carcinogenic [2]. These tire combustion emissions have been characterized into different classes depending on their composition i.e. both criteria and particulate emissions from tire combustion can represent significant short-term and long-term health hazards to individuals and the environment [3]. Since particulate matters are aggregates of small particulates, liquid droplets and vapors, they have been linked to respiratory and cardiovascular morbidity and mortality in vulnerable populations [4]. These particulates are of aerodynamic diameters, $\mathrm{PM}_{2.5}$ (particulate size $\leq 2.5$ micrometers) and $\mathrm{PM}_{10}$ (particulate size $\leq 10$ micrometers) [5]. Tire combustion results into volatiles which undergo degradation to produce free radicals considered biologically hazardous. PAH and oxy-PAHs metabolism in the body produces electrophilic and reactive metabolites that have been indicated as architects of pulmonary cytochrome P450 in diesel exhaust particles [6]. Furthermore, ambient airborne particulates consists of persistent free radicals and reactive oxygen species (ROS) associated in the generation of cellular oxidative stress and cell damage [7]. These ROS contributes much to decreased lung function and aggravates asthma, bronchitis, and pneumonia among people living in areas of high gaseous pollution [8] [9]. Depending on the extent and amount of exposure, these health effects could include irritation of the skin, eyes, and mucous membranes, respiratory effects, central nervous system depression, and cancer [10].

Histochemistry as the aspect of histology concerned with the identification of chemical components in biological cells and tissues has been used to explain more about soot effects in body organs [11]. To understand the impacts of particulate emissions in biological systems, there exist two major components to be analyzed; the first and most clinically important is the physiologic changes that occur and must be managed clinically to obtain optimum outcomes [12]. The second component relates to the biochemical changes responsible for the observed physiologic changes [13]. Consequently, histochemistry evaluates the soot emissions as an altering agent in the microstructures of the biological cells [14]. To appreciate the impacts of soot on biological structures, microscopy techniques such scanning electron microscopy (SEM), the electron microscope, and the light microscope are used in this study. Therefore, this work explores the biological impact of particulate emissions and organic volatiles from tire combustion on the lung tissues of male 
albino mice with the aim of developing an understanding on the pathological impacts as a consequence of inhaling such particulates by higher-order animals such as man. The information obtained is important in assisting clinicians and medical practioners to make informed decisions concerning environmental pollution from the thermolysis of organic materials. Generally, the toxic organic volatiles which are considered detrimental to biological systems have been discussed comprehensively in this study.

\section{Materials and Methods}

Clean tire samples were obtained from a tire waste yard and used without further treatment. The reagents used in this study were of analytical grade (purity $\geq 99 \%$ ). All reagents (methanol and dichloromethane) were purchased from Sigma Aldrich, Inc., St. Louis, Missouri, USA. Tire burning was conducted in a quartz reactor of dimensions $1.6 \mathrm{~cm}^{3}$ at 1 atmosphere pressure. The gas phase components were passed over dichloromethane (DCM) and transferred into $2 \mathrm{~mL}$ vials for analysis using a GC-MS.

\subsection{GC-MS Characterization of Molecular Volatiles from Combustion of Waste Tire}

Organic by-products from tire burning was passed through $10 \mathrm{~mL}$ dichloromethane solution (DCM), filtered using a filter paper (Whatmann No. 10) and investigated using Agilent 6890 Gas chromatograph connected to an Agilent mass selective detector (MSD), 5890 series. $1 \mu \mathrm{L}$ of filtered sample was injected into a GC column (DB-5MS, $30 \mathrm{~m} \times$ $250 \mu \mathrm{m} \times 0.5 \mu \mathrm{m})$. The temperature of the injector port was set at set at $200^{\circ} \mathrm{C}$ to enable the conversion of organic components to the gas-phase prior to MS analysis. Temperature programming was applied at a heating rate of $15^{\circ} \mathrm{C}$ for 10 minutes, holding for 1 minute at $200^{\circ} \mathrm{C}$, followed by a heating rate of $25^{\circ} \mathrm{C}$ for 4 minutes, and holding for 10 minutes at $300^{\circ} \mathrm{C}$. Electron Impact ionization energy of $70 \mathrm{eV}$ was used [15]. Molecular products were identified using the National Institute of Science and Technology software (NIST, USA) and confirmed by enhanced data incorporated into the Chemstation of Agilent's MSD. To ensure the correct compounds were reported, the peak shapes and the retention times of molecular products with those of pure compounds (standards) were compared, and found to match.

\subsection{SEM Characterization of Particulate Emissions}

Soot samples from tire were collected using a clean glass surface and carefully transferred into crimp top amber vials using a special brush free of impurities. Approximately $5 \mathrm{mg}$ of particulate sample was added to $1 \mathrm{~mL}$ methanol and gold grids were dipped into the sample. Twisters were used to pick the gold grids from the sample after trapping the particulate sample. The grids were then allowed to dry in air before putting them into the analysis chamber of the SEM (JEOL JMS 7100F) [16]. The sample was analyzed under high vacuum in order to minimize interference of air molecules during analysis. The SEM machine was then switched on and imaging of the sample was done at various magnifications by varying the resolution of the lens until a clear 
focus of the sample was observed. Image $J$ computer program was used to determine the size of the soot particles and a distribution curve of soot size was then determined using Igor. The mean sizes of the soot particles for tire emissions were reported and presented as a Gaussian distribution curve where the peak of the curve presents the average of the particle size.

\subsection{Mice Handling Particulate Exposure Protocol}

All animal studies reported in this work are approved by the Institutional Animal Care and Use Committee and conducted in accordance with the international guidelines established by the Association for Assessment and Accreditation of Laboratory Animal Care [17]. Five twelve-week old male mice weighing between $170 \mathrm{~g}$ to $200 \mathrm{~g}$ were purchased from Kenya medical research institute (KEMRI) and were housed in a pathogen-free environment (i.e. $20 \times 43 \times 18 \mathrm{~cm}$ polycarbonate cages with wire-top system containing Tech pellet/corn-cob bedding) at $19^{\circ} \mathrm{C}-26^{\circ} \mathrm{C}$ and $50 \% \pm 10 \%$ relative humidity with a 12-hour-light and 12-hour dark cycle. Three of the mice were used for tire exposure while two were used for control experiments. The mice were provided with chow and allowed to acclimatize for one week prior to the particulate exposure. The exposure protocol was conducted in such a way that it simulated approximate environmental air pollution conditions in polluted cities around the world. This was done for duration of two weeks with the assumption that the mice would survive the total exposure time.

During exposure periods, the wire-top lid of the mouse cage was replaced with a sealed top and high-efficiency airflow system to deliver gaseous particulates to the mice in their cages at a rate of $\sim 250 \mu \mathrm{gm}^{-3} \cdot \mathrm{day}^{-1}$. Mice were exposed to particulates from the different sources continually in order to simulate exposure of PM in the natural environment. This type of exposure protocol can be considered chronic because of the continuous exposure of particulate emissions to the mice. During exposure, the mice were provided with food pellets and water. Pulmonary response to exposure was evaluated after exposure protocol was complete.

\subsection{Histological Investigation}

Within 2 hours of completing the exposure protocol, control mouse was sacrificed by euthanizing with sodium pentobarbital/chloroform. This was followed by dissection in order to remove and examine the organs of interest (lungs) [18]. The trachea was exposed, cannulated, and secured with a suture. The lungs were immediately removed from the thorax and frozen in liquid nitrogen. After 24 hours, a portion of the lung tissue was homogenized in $0^{\circ} \mathrm{C}$ Tris-hydro-chloride $(\mathrm{HCl})$ buffers $(25 \mathrm{mM}$ Tris, $1 \mathrm{mM}$ EDTA). The lung samples were lavaged four times with a single volume of phosphate-buffered saline and then analyzed for biological damage caused by particulate emissions.

\section{Results}

\subsection{Molecular Organics from the Thermal Degradation of Tire}

In this study, it was established that the aromatic content of tire emissions were the 
dominant by-products of tire combustion. In addition, the inhaled particulates may be responsible for the observed pathological effects on the lung tissues of the mice exposed to this type of emissions. Various PAHs were detected from the combustion by-products of tire as presented in Table 1 (tire combustion by products). The corresponding GC-MS chromatograms for the organic volatiles from combustion of tire are accordingly reported in Figure 1.

Evidently from this study, the intensity of particulate emissions was very high hence it can be concluded that tire burning generates a lot of soot which is hazardous. The detection of cyclopentafused PAHs in the combustion of tire (fluorene) is an indication that tire particulate emissions are very toxic. This is because cyclopentafused PAHs are more bio-active than their analogous PAHs without the cyclopenta moiety [19].

Table 1. Organic volatiles form the thermal degradation of tire.

\begin{tabular}{|c|c|c|c|c|}
\hline No & Molecular toxin & $\begin{array}{l}\text { Molecular } \\
\text { structure }\end{array}$ & Retention (mins) & $\begin{array}{l}\text { Molecular formula } \\
\text { mass }(\mathrm{g} / \mathrm{mol})\end{array}$ \\
\hline i & benzene & & 16.12 & 78.05 \\
\hline ii & benzaldehyde & & 18.41 & 106.04 \\
\hline iii & propylcyclohexane & & 19.35 & 126.14 \\
\hline iv & benzofuran & & 20.15 & 118.13 \\
\hline $\mathbf{v}$ & fluorene & & 20.43 & 166.22 \\
\hline vi & anthracene & & 20.51 & 178.08 \\
\hline vii & pyrene & & 22.40 & 202.08 \\
\hline
\end{tabular}

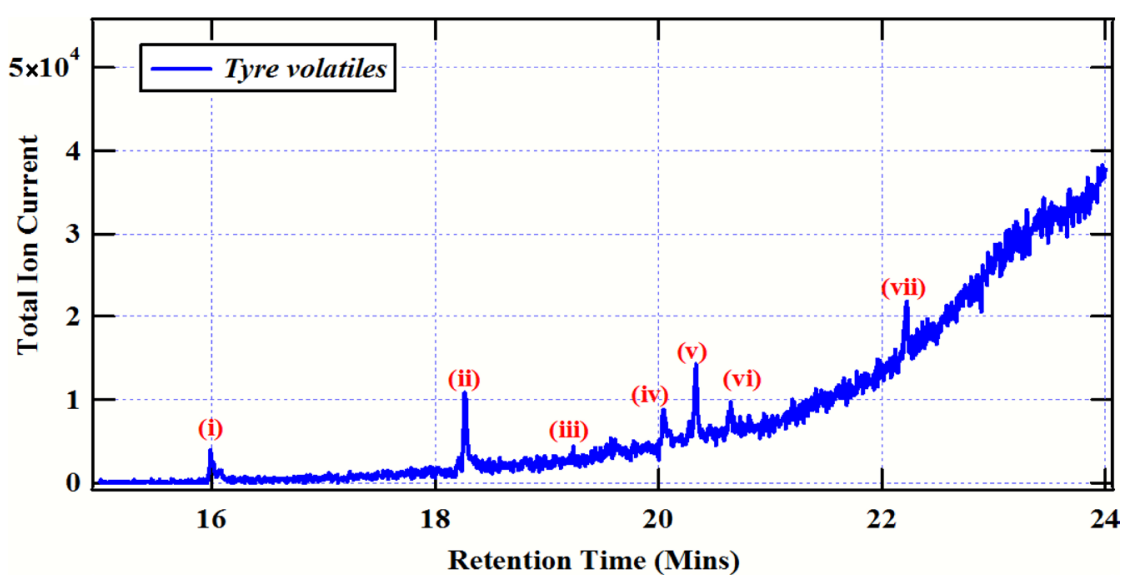

Figure 1. GC-MS chromatogram for organic volatiles from tire burning. 
A few oxygenated compounds also considered xenobiotic and eco-toxicants because of their bio-activity were detected in this investigation. This included benzaldehyde and benzofuran.

It was noted however, that numerous straight chain alkanes such as tetracosane, pentacosane, decaline, nonane, and decane (although of very low intensity) were detected in our experiments. Straight chain alkanes are also well known components of particulate emissions and are conventionally established organic toxicants.

\subsection{Particulate Emission Characterization}

At a magnification of $400 \times$, the particulate emissions of tire were examined using a scanning electron microscope. The micrographs of tire particulates were remarkably interesting as it was quite difficult to obtain a clear image in the whole range of magnification. However, after several attempts a fairly neat image was obtained. Image $J$ was used to measure the sizes of the emission particulates and size distribution was determined using Igor graphical software. The mean diameter of the particulate size of soot from tire burning was quite large $(\sim 16.23 \pm 3.36 \mu \mathrm{m})$, Figure 2, vide infra. Notably, to obtain enough data points to plot size distribution curves, several micrographs taken at the same magnification were utilized. From the micrographs reported in this study, tire particulate emissions appear to be larger. However, emissions size fall within the $\mathrm{PM}_{10}$ category of airborne particulates. Although, these particulates are fairly, large and may not be inhaled deeper into the respiratory system, their deposition on the respiratory surface for instance the lung tissues (microphages and alveoli) may inflict serious biological damage. These deposits may act as growth centers of tumours, accelerate cancer, oxidative stress, and cardiopulmonary death. Based on the results reported in this work, $\mathrm{PM}_{10}$ are equally toxic in comparison to $\mathrm{PM}_{2.5}$ and other ultrafine particulates. Nonetheless, the particulate size may not be enough reason for the observed inflammations noted in the lungs of albino mice exposed to these soot particulates. There must be some organic toxics and probably intermediate reactive species including organic radicals capable of causing cell injury and eventually the growth of tumors. These proposed predictions are clearly displayed in Figure 3, vide infra.

Since the principal source of airborne fine particles from combustion carry with them free radicals, it is evident that free radicals may induce cellular and alveolar damage and ultimately causing tumors, cancer, and death [20] not only in research animals but also higher order animals including man. In general, the surface area of inhaled particulates is more decisive of their toxicity than their size, and smaller particles tend to have a larger relative surface area, for instance, those sized 10 microns or less.

\subsection{Decomposition Profile of Waste Tire}

The lowest mass loss from tire combustion was recorded at a temperature of $200^{\circ} \mathrm{C}$ and $550^{\circ} \mathrm{C}$. This means that the temperature of $200^{\circ} \mathrm{C}$ is not sufficient to effect evolution of organic volatiles. Again at $500^{\circ} \mathrm{C}$ most volatiles had been emitted at temperatures between $250^{\circ} \mathrm{C}$ and $500^{\circ} \mathrm{C}$. These mass loss effects are well shown in the curve below. In- 

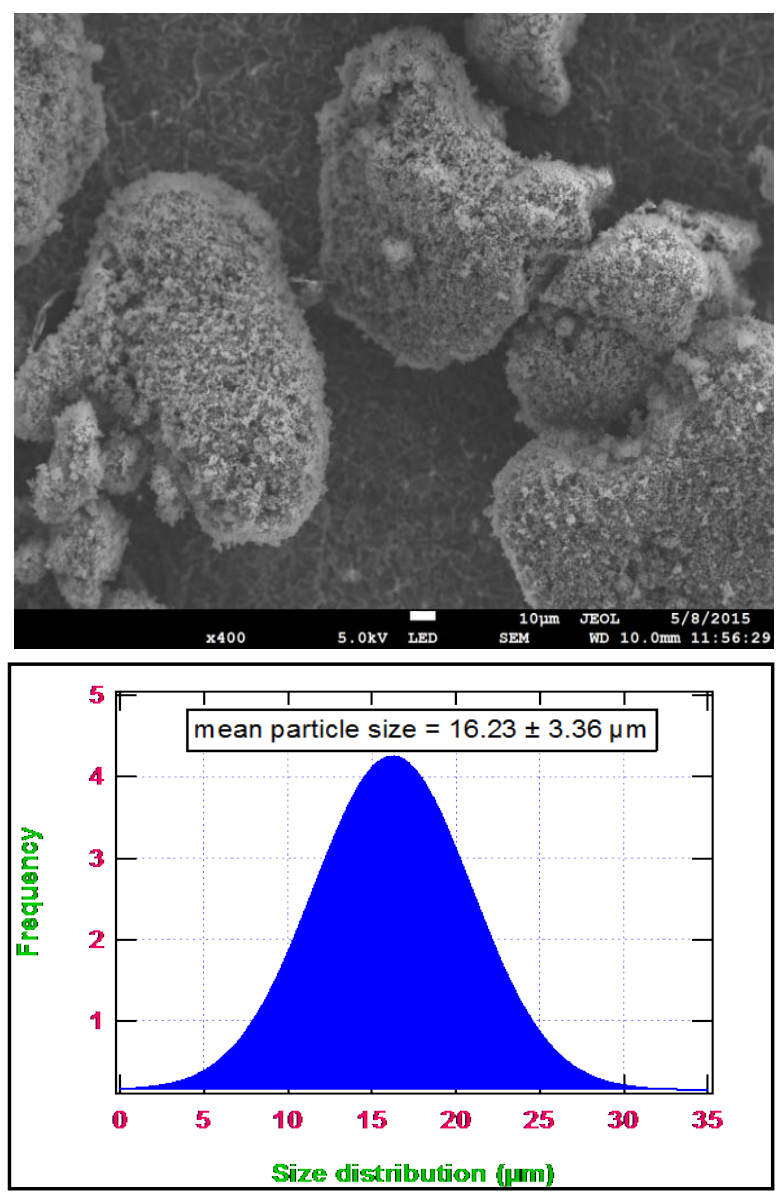

Figure 2. SEM image and particle size distribution (Gaussian blue) of soot particles from tire burning.

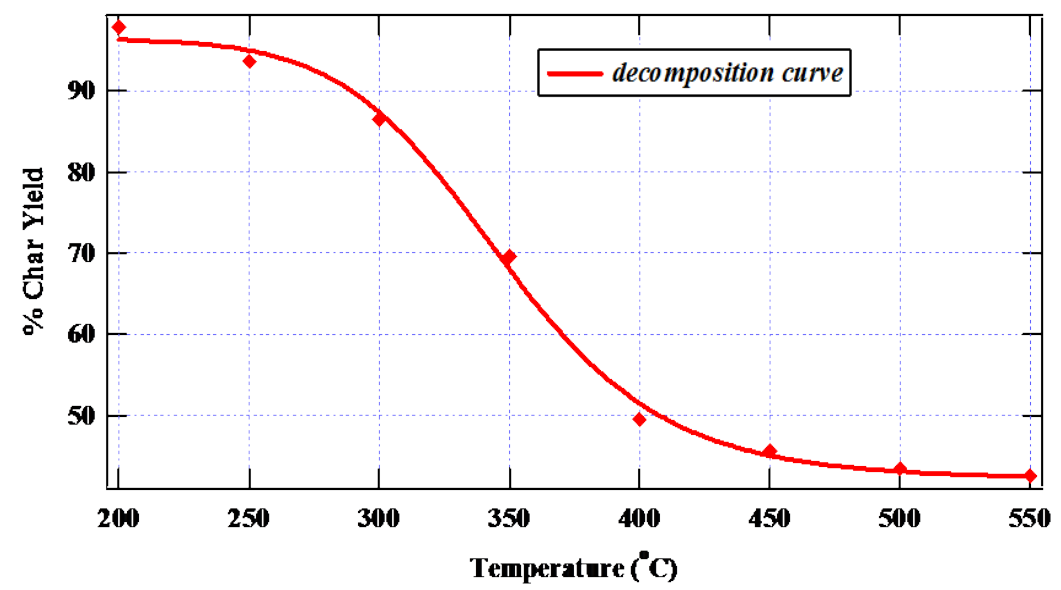

Figure 3. Char percentage (\%) yield from thermal degradation of tyre.

itially, there was a slight decrease in percentage char yield at $200^{\circ} \mathrm{C}$ and $250^{\circ} \mathrm{C}$. However, between $300^{\circ} \mathrm{C}$ and $500^{\circ} \mathrm{C}$ there was drastic change in \% yield.

The decrease may be associated with high mass loss due to emission of moisture and volatiles especially PAHs such as fluorene and fluoranthene. This observation is in 
agreement with other results of biomass and tire combustion which indicate high mass loss occurs between $400^{\circ} \mathrm{C}$ and $500^{\circ} \mathrm{C}$ [21]. The mass loss between $300^{\circ} \mathrm{C}$ and $500^{\circ} \mathrm{C}$ was $\sim 39 \%$. This region corresponds to the zone of highest release of molecular organics. Thus, at $500^{\circ} \mathrm{C}$ most organic compounds will have been released so that any further increase in temperature results in sharp decrease in the thermal degradation products (Figure 3). These results corroborates previous data reported in literature on the thermal degradation of tire [22] [23].

\subsection{Lung Damage Examination after Tire Particulate Exposure}

In order to understand the inhalation toxicity of tire particulates, lungs of albino mice were examined by a light microscopy interfaced with a computer to assess the effects on the tissues. After sections of $3-4-\mu \mathrm{m}$ thick were cut and stained with hematoxylin and eosin ( $\mathrm{H} \& \mathrm{E})$, they were examined histologically. One exposure-related major finding we apparent in comparison to the control lung sample (Figure 4(A), vide infra) i.e. Maximal to mild yellow-brown to black pigmentation within the alveolar macrophages following a 7 days exposure of tire particulates (Figure 4(B) and Figure 4(C)).

The alveolar histiocytosis was characterized by slightly increased number of alveolar macrophages that in general were diffusely distributed throughout the lung. The pigmented particulates found in the alveolar macrophages from the recovery animals were more commonly observed in punctate aggregates, possibly reflecting continued cellular processing of the material. Histopathological effects in the lung following exposure to the tire combustion shows that the control mouse exposed to ambient air for 14 days had normal alveolar air spaces and septa (Figure 4(A)).

Air spaces contain scattered pulmonary interstitial macrophages. The mice exposed to tire emissions died after 7 days. Clearly, as observed in Figure 4(B) and Figure 4(C), pulmonary alveolar macrophages contained dark yellow to black intracytoplasmic pigments. Deposition of soot particulates (black pigments) can be noted in Figure 4(B) and Figure 4(C).

\section{Discussion}

Tire combustion revealed varying concentrations of the various compounds, for exam-

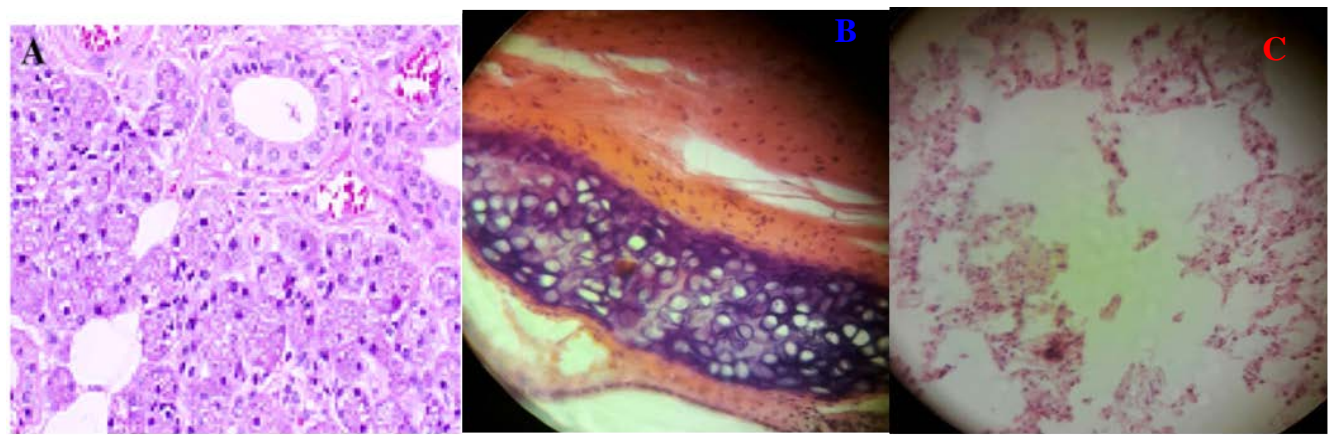

Figure 4. (A) is the control lung tissue, (B) is the transverse section of the mice lung tissue exposed to tire particulates and $(\mathrm{C})$ is the cross-sectioned lung tissue exposed to tire particulates. 
ple, benzaldehyde, fluorene and pyrene had the highest concentrations. These results imply that tire combustion mainly generates PAHs as the major organic volatiles. It is evident therefore from this work that tire combustion by-products are mainly PAHs, some of which have been linked tovarious biological illnesses.

The detection of cyclopentafused PAHs (fluorene and fluoranthene) is an indication that tire particulate emissions are very toxic. This is because cyclopentafused PAHs are more bio-active than their analogous PAHs without the cyclopenta moiety [19]. Fluorene was also detected in tire burning. A few oxygenated compounds also considered xenobiotic and eco-toxicants because of their bio-activity were detected in this investigation. These included benzaldehyde and benzofuran. However, it was noted that numerous straight chain alkanes such as tetracosane, pentacosane, decaline, nonane, and decane (although of very low intensity) were detected in our experiment. Straight chain alkanes are also well known components of particulate emissions and are conventionally established organic toxicants.

$\mathrm{PAH}$ have been previously identified in tire combustion and given the negative health impacts associated with them, their concentrations are of considerable interest. However, not all PAHs are of the same toxicity. The structure of a particle and the substituted groups determine harmful properties of PAHs. Many PAHs belong to the group of carcinogens, in particular the unsubstituted PAHs as well as the nitrated and methylated ones, and those containing the carboxylic group. Sulphur based compounds were detected in low concentrations and included phenylmethanethiol and benzenethiol. Nonetheless, we believe a significant amount of sulphur dioxide was evolved during the thermal degradation of tire and this may contribute to some pathological problems observed in the lung tissues of albino mice. This is because; conventionally sulphur is a major component in tire manufacture.

\subsection{Oxygenated Organic Volatiles}

Combustion of tires also generates analogs of cyclic and polycyclic aromatic hydrocarbons that contain heteroatoms [24]. An oxygenated PAH (oxy-PAH) is a PAH with one or more carbonyl functional groups. Examples of oxy-PAH structures detected in this work are shown in Figure 5 below.

Oxy-PAHs have been measured in the environment and are detected in particulate matter emitted by combustion sources such as waste incineration, petrol and diesel emissions, bio-mass burning and tire combustion which are inclusive in this study. Oxy-PAHs have also been shown to undergo some reactions (secondary reactions) as a result of parental PAHs combining with atmospheric oxidants like hydroxyl radicals.

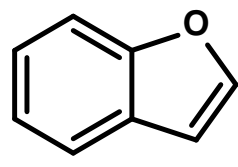

benzofuran

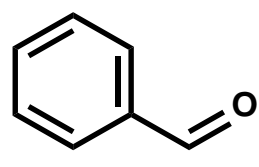

benzaldehyde

Figure 5. Oxygenated volatiles detected in this study. 


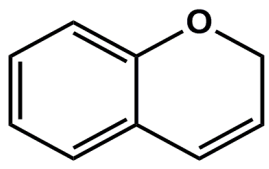

\section{H-1-Benzopyran}

Figure 6. Molecular compound of environmental concern (2H-Benzopyran).

The presence of heteroatoms in these polycyclic compounds changes their interactions with biological tissues, giving them different health effects, when compared to PAH. Carbonyl functional groups on $\mathrm{PAH}$ do not increase mutagenic properties of these compounds however their oxyl radical can cause serious cellular damage.

Interesting molecular compounds of environmental concern were also identified as minor products, for instance, $2 \mathrm{H}$-benzopyran. This compound is of great interest because of its characteristic behavior to cause serious environmental and biological concerns. At reasonably high temperatures and in presence of small amounts of chlorine and a transition metal such as iron or copper, it can convert into the most toxic class of compounds referred to as benzofurans usually implicated in various poisoning episodes of humans and animals [25]-[28], and are by far the most dangerous organic toxins to be identified in the environment in recent times. Figure 6 presents the molecular structure of $2 \mathrm{H}$-benzopyran which has the ability to convert into benzofurans under conditions desirable for the formation of such compounds [29].

\subsection{Histochemistry of Tire Emissions Exposed Lungs}

Histochemistry is conventionally defined as the study, identification, and distribution of chemical compounds within and between biological cells using histological techniques such as histological stains, indicators, light and electron microscopy. This study proposes that soot emissions alone may not be responsible for the observed effects noticed in Figure 4(B) and Figure 4(C), vide supra. From the GC-MS data, copious classes of toxic organic volatiles are also released during the thermolysis of tire samples and may contribute significantly to cell damage, development of tumors, and ultimately death. Nevertheless, soot may also be precursors of health impacts probably because of the organic radicals bound to the surface of the soot particles. This observation is evident in this study because tire emissions accelerated the death of the mouse exposed to it notwithstanding the few organic volatiles detected during its combustion.

The respiratory tract epithelium which normally begins at the nares and extends to the alveoli and its cellular composition conventionally varies significantly by function and structural site along the respiratory path. Volatiles carried into the respiratory tract are known to pass over epithelial cells in the nares [30]. These cells represent a natural block whose function is the removal of inhaled extraneous substances. They are the primary cells to exhibit the adverse consequences of exposure to inhaled particulates and hence may serve as a sensitive and direct measure of particle toxicity [31] as observed in Figure 4, videsupra. Epithelial cells lining the tracheobronchial tree, central 
acini, and alveoli of the lungs also serve as sensitive indicators of the pattern of induced injury due to soot deposition and subsequent particle-mediated events in these regions. Two important sites for particle deposition in the lungs include the respiratory bronchioles and the central acini. These two sites showed significant damage as shown in Figure 4(B) and Figure 4(C). These structures form the transitional zone between the air conduction path and gas exchange alveoli. In mice, the transition from the terminal bronchiole to the alveolar duct is immediate [32]. In contrast, humans possess a more complex transitional zone, with one to three generations of airways. Because the respiratory bronchioles and central acini are primary sites for lung injury after exposure to airborne pollutants [33], it is critical to understand the effects of particle deposition on structural and functional changes in this region [34].

This study has demonstrated that tire soot inhalation for a substantial period (i.e. 7 days of particulate exposure) of time aggravates the neutrophilic lung swelling or proinflammatory chemokine expressions related to lung dysfunction. Nevertheless, the lung pathology observed in the mice following the experimental exposures to tire particulate emissions showed significant change in airway epithelial, necrosis, and parenchymal congestion, edema, hemorrhage and inflammation (cf. Figure 4(B) and Figure $4(C)$ ). However, the microscopic examination of lung sections indicated marked differences between the lungs of exposed mice, and the control (Figures 4(A)-(C)). A great accumulation of soot particles was found surrounding the bronchioles in the lymphatics, with the adjacent alveolar wall structures frequently absent in the lungs exposed to gaseous pollutants. This condition is similar anatomically to that of the centrilobular emphysema as reported in literature [35].

From Figure 4(B) and Figure 4(C), it is clear that particulate emissions generated by tire burning exhibited extensive destruction to the tissues. This is because of evident damage to the cells which was significant: capillary disconnection and blockage of air pathways (cf. Figure $4(C)$ ). Moreover, noticeable inflammation was observed in the lung tissues. Focal airway epithelial necrosis was found in the trachea and with decreasing frequency distally not noticed in terminal bronchioles. The damage to the endothelium and the alveolar epithelium resulted in the creation of an open interface between the lung and the blood which facilitated the spread of soot particulates from the lung systemically, and ultimately a systemic inflammatory response [36].

\section{Conclusion}

This study has shown that exposure of tire particulates to albino mice have a severe impact on lung tissues. This observation may be extrapolated to higher order animals such as man and may evidently explain the cause of various respiratory problems such as asthma and bronchitis. There is also the production of mutagenic as well as carcinogenic compounds such as PAHs-benzene, anthracene, pyrene, and cyclopentafused PAHs (fluorene) as reported in this study and literature data. These organic toxicants are possible precursors that may disrupt the normal lining of the respiratory tract and cause potential swelling, airway collapse, and respiratory distress. This contribution has 
also shown that particulates from tire combustion are slightly greater than $\mathrm{PM}_{10}$ particulates.

\section{Acknowledgements}

This study was partially funded by the directorate of research and extension of Egerton University. Miss Anne of Moi Teaching and Referral Hospital (MTRH) is credited for the valuable information included in this work.

\section{References}

[1] Mmereki, D., Baldwin, A., Hong, L. and Li, B. (2016) Handling Scrap Tyres in Botswana: Initiatives, Practices, and Consequences. Journal of Solid Waste Technology \& Management, 42.

[2] Downard, J., Singh, A., Bullard, R., Jayarathne, T., Rathnayake, C.M., Simmons, D.L., Wels, B.R., Spak, S.N., Peters, T. and Beardsley, D. (2015) Uncontrolled Combustion of Shredded Tires in a Landfill-Part 1: Characterization of Gaseous and Particulate Emissions. Atmospheric Environment, 104, 195-204. http://dx.doi.org/10.1016/j.atmosenv.2014.12.059

[3] Tsai, W.-T. (2016) Toxic Volatile Organic Compounds (VOCs) in the Atmospheric Environment: Regulatory Aspects and Monitoring in Japan and Korea. Environments, 3, 23. http://dx.doi.org/10.3390/environments3030023

[4] Thurston, G. and Lippmann, M. (2015) Ambient Particulate Matter Air Pollution and Cardiopulmonary Diseases. Seminars in Respiratory and Critical Care Medicine. Thieme Medical Publishers.

[5] Mirowsky, J., Hickey, C., Horton, L., Blaustein, M., Galdanes, K., Peltier, R.E., Chillrud, S., Chen, L.C., Ross, J. and Nadas, A. (2013) The Effect of Particle Size, Location and Season on the Toxicity of Urban and Rural Particulate Matter. Inhalation Toxicology, 25, 747-757. http://dx.doi.org/10.3109/08958378.2013.846443

[6] Murphy, J., Rouse, R., Polk, W., Henk, G., Barker, A., Boudreaux, J., Floyd, Z. and Penn, A. (2008) Combustion-Derived Hydrocarbons Localize to Lipid Droplets in Respiratory Cells. American Journal of Respiratory Cell and Molecular Biology, 38, 532-540. http://dx.doi.org/10.1165/rcmb.2007-0204OC

[7] Li, N., Xia, T. and Nel, A.E. (2008) The Role of Oxidative Stress in Ambient Particulate Matter-Induced Lung Diseases and Its Implications in the Toxicity of Engineered Nanoparticles. Free Radical Biology and Medicine, 44, 1689-1699.

http://dx.doi.org/10.1016/j.freeradbiomed.2008.01.028

[8] Perez-Padilla, R., Schilmann, A. and Riojas-Rodriguez, H. (2010) Respiratory Health Effects of Indoor Air Pollution [Review Article]. The International Journal of Tuberculosis and Lung Disease, 14, 1079-1086.

[9] Ko, F.W. and Hui, D.S. (2012) Air Pollution and Chronic Obstructive Pulmonary Disease. Respirology, 17, 395-401. http://dx.doi.org/10.1111/j.1440-1843.2011.02112.x

[10] Kura, B., Verma, S., Ajdari, E. and Iyer, A. (2013) Growing Public Health Concerns from Poor Urban Air Quality: Strategies for Sustainable Urban Living. Computational Water, Energy, and Environmental Engineering, 2, 1. http://dx.doi.org/10.4236/cweee.2013.22B001

[11] Vohr, H.-W. (2016) The Challenge of Predicting the Immunotoxic Potential of Chemicals, in Environmental Influences on the Immune System. Springer, 321-340.

[12] Bates, J.T., Weber, R.J., Abrams, J., Verma, V., Fang, T., Klein, M., Strickland, M.J., Sarnat, S.E., Chang, H.H. and Mulholland, J.A. (2015) Reactive Oxygen Species Generation Linked 
to Sources of Atmospheric Particulate Matter and Cardiorespiratory Effects. Environmental Science \& Technology, 49, 13605-13612. http://dx.doi.org/10.1021/acs.est.5b02967

[13] Bergethon, P.R. (2013) The Physical Basis of Biochemistry: The Foundations of Molecular Biophysics. Springer Science \& Business Media.

[14] Jain, K.K. (2012) The Handbook of Nanomedicine. Springer Science \& Business Media. http://dx.doi.org/10.1007/978-1-61779-983-9

[15] Kibet, J. (2012) Molecular Products and Radicals from Pyrolysis of Lignin. Environmental Science \& Technology, 46. http://dx.doi.org/10.1021/es302942c

[16] Ganesh, V.A., Dinachali, S.S., Nair, A.S. and Ramakrishna, S. (2013) Robust Superamphiphobic Film from Electrospun $\mathrm{TiO}_{2}$ Nanostructures. ACS Applied Materials \& Interfaces, 5, 1527-1532. http://dx.doi.org/10.1021/am302790d

[17] Goodman, J.R. (2015) The Association for Assessment and Accreditation of Laboratory Animal Care International Fails to Meaningfully Address Concerns Regarding Its Accreditation Program. Journal of Applied Animal Welfare Science, 18, 314-315. http://dx.doi.org/10.1080/10888705.2015.1040922

[18] Pryor, W.A., Stone, K., Zang, L.Y. and Bermudez, E. (1998) Fractionation of Aqueous Cigarette Tar Extracts: Fractions That Contain the Tar Radical Cause DNA Damage. Chemical Research in Toxicology, 11, 441-448. http://dx.doi.org/10.1021/tx970159y

[19] Labota, M.J., Kaats-Richtersa, V.E.M., Kopera, C., Vlietstraa, E.J., Havenithb, R.W.A., Jenneskensa, L.W. and Seinenc, W. (2005) CP-Arene Oxides: The Ultimate, Active Mutagenic forms of Cyclopenta-Fused Polycyclic Aromatic Hydrocarbons (CP-PAHs). Mutation Research, 581, 115-132. http://dx.doi.org/10.1016/j.mrgentox.2004.11.014

[20] Kelley, M.A., Hebert, V.Y., Thibeaux, T.M., Orchard, M.A., Hasan, F., Cormier, S.A., Thevenot, P.T., Lomnicki, S.M., Varner, K.J. and Dellinger, B. (2013) Model Combustion-Generated Particulate Matter Containing Persistent Free Radicals Redox Cycle to Produce Reactive Oxygen Species. Chemical Research in Toxicology, 26, 1862-1871. http://dx.doi.org/10.1021/tx400227s

[21] Sharma, R.K. and Hajaligol, M.R. (2003) Effect of Pyrolysis Conditions on the Formation of Polycyclic Aromatic Hydrocarbons (PAHs) from Polyphenolic Compounds. Journal of Analytical and Applied Pyrolysis, 66, 123-144. http://dx.doi.org/10.1016/S0165-2370(02)00109-2

[22] Kibet, J.K., Khachatryan, L. and Dellinger, B. (2015) Phenols from Pyrolysis and Co-Pyrolysis of Tobacco Biomass Components. Chemosphere, 138, 259-265. http://dx.doi.org/10.1016/j.chemosphere.2015.06.003

[23] Ding, K., Zhong, Z., Zhang, B., Song, Z. and Qian, X. (2015) Pyrolysis Characteristics of Waste Tire in an Analytical Pyrolyzer Coupled with Gas Chromatography/Mass Spectrometry. Energy \& Fuels, 29, 3181-3187. http://dx.doi.org/10.1021/acs.energyfuels.5b00247

[24] May, A.A., Saleh, R., Hennigan, C.J., Donahue, N.M. and Robinson, A.L. (2012) Volatility of Organic Molecular Markers Used for Source Apportionment Analysis: Measurements and Implications for Atmospheric Lifetime. Environmental Science \& Technology, 46, 12435-12444. http://dx.doi.org/10.1021/es302276t

[25] Evans, C.S. and Dellinger, B. (2003) Mechanisms of Dioxin Formation from the HighTemperature Pyrolysis of 2-Bromophenol. Environmental Science \& Technology, 37, 55745580. http://dx.doi.org/10.1021/es034387s

[26] Evans, C.S. and Dellinger, B. (2005) Mechanisms of Dioxin Formation from the HighTemperature Oxidation of 2-Bromophenol. Environmental Science \& Technology, 39, 2128-2134. http://dx.doi.org/10.1021/es048461y

[27] Kibet, J., Khachatryan, L. and Dellinger, B. (2012) Molecular Products and Radicals from 
Pyrolysis of Lignin. Environmental Science \& Technology, 46, 12994-13001. http://dx.doi.org/10.1021/es302942c

[28] Nganai, S., Lomnicki, S. and Dellinger, B. (2012) Formation of PCDD/Fs from Oxidation of 2-Monochlorophenol over an $\mathrm{Fe}_{2} \mathrm{O}_{3}$ /Silica Surface. Chemosphere, 88, 371-376.

http://dx.doi.org/10.1016/j.chemosphere.2012.03.060

[29] Kibet, J., Khachatryan, L. and Dellinger, B. (2013) Molecular Products from the Pyrolysis and Oxidative Pyrolysis of Tyrosine. Chemosphere, 91, 1026-1034.

http://dx.doi.org/10.1016/j.chemosphere.2013.01.071

[30] Barile, F.A. (2013) Principles of Toxicology Testing. CRC Press, Boca Raton.

[31] Landsiedel, R., Sauer, U.G., Ma-Hock, L., Schnekenburger, J. and Wiemann, M. (2014) Pulmonary Toxicity of Nanomaterials: A Critical Comparison of Published in Vitro Assays and in Vivo Inhalation or Instillation Studies. Nanomedicine, 9, 2557-2585.

http://dx.doi.org/10.2217/nnm.14.149

[32] Townsley, M.I. (2012) Structure and Composition of Pulmonary Arteries, Capillaries, and Veins. Comprehensive Physiology, 2, 675-709. http://dx.doi.org/10.1002/cphy.c100081

[33] Adamson, I.Y., Vincent, R. and Bjarnason, S.G. (1999) Cell Injury and Interstitial Inflammation in Rat Lung after Inhalation of Ozone and Urban Particulates. American Journal of Respiratory Cell and Molecular Biology, 20, 1067-1072.

http://dx.doi.org/10.1165/ajrcmb.20.5.3468

[34] Pinkerton, K.E. and Joad, J.P. (2000) The Mammalian Respiratory System and Critical Windows of Exposure for Children's Health. Environmental Health Perspectives, 108, 457 462. http://dx.doi.org/10.1289/ehp.00108s3457

[35] Witschi, H. (2000) Environmental Agents Altering Lung Biochemistry. Federation Proceedings, 36, 1631-1634.

[36] Morrison, R. and Bidani, A. (2002) Acute Respiratory Distress Syndrome Epidemiology and Pathophysiology. Chest Surgery Clinics of North America, 12, 301-323. http://dx.doi.org/10.1016/S1052-3359(02)00004-2

\section{Submit or recommend next manuscript to OALib Journal and we will provide best} service for you:

- Publication frequency: Monthly

- 9 subject areas of science, technology and medicine

- Fair and rigorous peer-review system

- Fast publication process

- Article promotion in various social networking sites (LinkedIn, Facebook, Twitter, etc.)

- Maximum dissemination of your research work

Submit Your Paper Online: Click Here to Submit

Or Contact service@oalib.com 